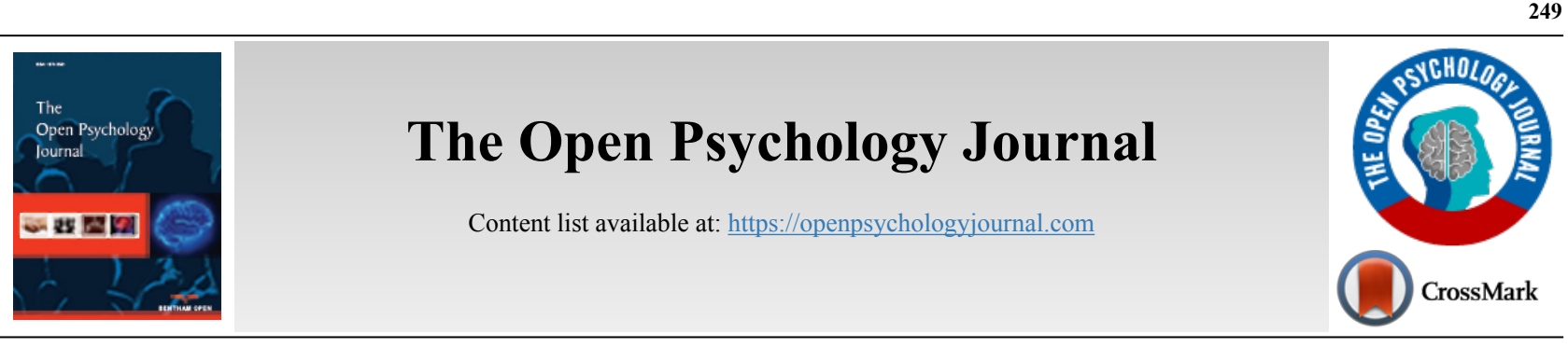

RESEARCH ARTICLE

\title{
Depression, Anxiety and Stress Levels among Chronic Disease Patients During COVID-19 Pandemic in Dessie Town Hospitals, Ethiopia
}

\author{
Sisay Gedamu Addis ${ }^{1, *(D)}$, Abebe Dires Nega ${ }^{1}$ and Debrnesh Goshiye Miretu ${ }^{2}$

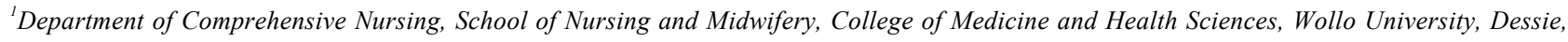 \\ Ethiopia \\ ${ }^{2}$ Department of Pediatric and Child Health Nursing, School of Nursing and Midwifery, College of Medicine and Health Sciences, Wollo University, \\ Dessie, Ethiopia
}

\begin{abstract}
:
Introduction:

Coronavirus disease 2019 was first detected in China in December 2019. In Ethiopia, depression, anxiety, and stress levels of chronic disease patients were not known during COVID-19. Thus, this study aimed to assess depression, anxiety, and stress levels of chronic disease patients in government and private hospitals of Dessie town during COVID-19.

\section{Methods:}

Hospital-based cross-sectional study design was used. The Depression Anxiety and Stress Scale-21 was used to measure depression, anxiety, and stress of chronic disease patients during the current pandemic. Both binary and multivariate logistic regression analyses were performed to identify factors, and a significant association was declared at $\mathrm{p}$-value $<0.05$ in multivariate analysis.

\section{Results and Discussion:}

The overall anxiety, depression, and stress level were $19.9 \%, 21.5 \%$, and $17.7 \%$, respectively. In multivariate analysis, older age, female gender, urban residency, duration of living with chronic diseases, and presence of comorbidities were associated with depression of chronic disease patients during the pandemic at p-value $<0.05$. Age, female gender, presence of comorbidities, and no social support were associated with anxiety. Urban residency, use of hand sanitizer, those who had respiratory manifestations, and travel history in the last two weeks were significantly associated with stress levels.

\section{Conclusion:}

A significant number of chronic disease patients had depression, anxiety, and stress during the COVID-19 pandemic. Therefore, governmental and non-governmental organizations, health professionals, media, and hospital administrators should be involved to decrease the depression, anxiety, and stress of chronic disease patients during the pandemic. Moreover, we encourage researchers to conduct comparative longitudinal studies to assess depression, anxiety, and stress levels of chronic disease patients before and after the onset of the COVID-19 pandemic.
\end{abstract}

Keywords: Depression, Anxiety, Stress, Chronic disease patient, COVID-19, Dessie town.

\section{Article History}

Received: January 9, 2021

Revised: June 8, 2021

Accepted: July 2, 2021

\section{INTRODUCTION}

Severe Acute Respiratory Syndrome Coronavirus-2 (SARS-CoV-2) is the etiology of COVID-19. This virus was first reported in China in December 2019, and it has been spreading globally. On March 11, 2020, WHO announced COVID-19 as a universal pandemic [1].

\footnotetext{
* Address correspondence to this author at the Department of Comprehensive Nursing, School of Nursing and Midwifery, College of Medicine and Health Sciences, Wollo University, P.O.BOX:1145, Dessie, Ethiopia;

Tel: +251920553732; E-mail: sgsisay4@gmail.com
}

COVID-19 is mainly a respiratory disease that is manifested by cough, fever, dyspnea, fatigue, myalgia, headache, chills, and sore throat. Patients with symptoms of shortness of breath and anorexia may require intensive care units. At the time of admission, only $44 \%$ of patients infected with the novel coronavirus had a fever, but about $89 \%$ would be febrile during hospitalization [2 - 4].

This disease ranges from mild symptoms to severe diseases like Disseminated Intravascular Coagulation (DIC), Acute Respiratory Distress Syndrome (ARDS), renal failure, and 
septic shock. Novel coronavirus infection is more severe in older age populations who have chronic diseases like diabetes mellitus, kidney disease, chronic lung diseases, and liver diseases. In addition, patients with high body mass index and those taking immunosuppressant medications are at higher risk of COVID-19 morbidity and mortality [5, 6]. Furthermore, another study revealed that people with hypertension, diabetes mellitus, diseases of the heart and lung were highly affected by COVID-19 [7].

COVID-19 is a highly contagious disease that can be transmitted mainly through close contacts [8 - 11]. This pandemic affected many people throughout the world. At the time of writing this manuscript (as of September 3, 2020), about 25.6 million people have been affected by COVID-19, and 852,752 deaths were recorded. At the same time, in Ethiopia, a total of 53,304 people were infected, and 828 deaths were reported [12]. COVID-19 is not only an infectious disease but also a shock to the major economies of the world [13].

Until the present date, there was no confirmed medication reported from anywhere to treat COVID-19. However, WHO recommended different prevention strategies which focused on rapid case finding and management, follow-up of cases and awareness creation, prevention, and control of infection, quarantine of travelers, and other public health interventions $[14,15]$.

COVID-19 is not only a disease, but it has also affected the financial sector and caused political and social issues [13, 16 20]. In addition, the disease has affected the health care system of Africa, including Ethiopia [21 - 23]. During the current pandemic, various studies were done to assess depression, stress, and anxiety level in the general population [24 - 32]. As per our knowledge, until data collection of this study, there were no published studies in Ethiopia on depression, anxiety and stress levels of patients with the chronic disease during the pandemic. Thus, the objective of this study was to assess depression, anxiety, and stress levels of chronic disease patients in Dessie town government and private hospitals. The result of the study may help policymakers and health care workers in formulating comprehensive interventions to improve the mental health of chronic disease patients. Furthermore, this study provides valuable information to Dessie town and South Wollo zone health office, health professionals, and policymakers to plan their resources and implement accordingly.

\section{METHODS}

\subsection{Study Area}

This study was carried out in the Dessie town government and private hospitals. Dessie town is situated $401 \mathrm{~km}$ North of Addis Ababa in a mountainous landscape, and it is about 480 $\mathrm{km}$ from Bahirdar (capital city of Amhara regional sate). Dessie town has two government and three private hospitals. These government and private hospitals serve South Wollo zone, North Wollo Zone, and some parts of the Afar region population.

\subsection{Study Design and Period}

A facility-based cross-sectional study was done from July 20 to August 5, 2020.

\subsection{Source Population}

All chronic disease clients who attended inpatient departments and outpatient clinics in Dessie town government and private hospitals were the source population.

\subsection{Study Population}

All chronic disease patients who attended selected Dessie town government and private hospitals during the study period were the study population.

\subsection{Inclusion Criteria}

All patients with chronic disease aged 18 years and above who visited government and private hospitals in Dessie town during the study period were included.

\subsection{Exclusion Criteria}

Critical ill and hearing impairment patients were excluded.

\subsection{Sample Size Determination}

It is calculated by using single proportion formula $[\mathrm{n}=(\mathrm{Z}$ $\left.\mathrm{a} / 2)^{2} \mathrm{P}(1-\mathrm{P}) / \mathrm{d}^{2}\right]$. A proportion of $50 \%$ was used because there were no published data on chronic diseases patients' depression, anxiety, and stress level during the pandemic in our country up to the date of data collection of this study, $95 \%$ confidence level $(\mathrm{Z}=1.96), 5 \%$ margin of error, and $10 \%$ nonresponse rate. Thus, the final sample size was 422 .

\subsection{Sampling Technique and Procedure}

In Dessie town, there are five hospitals. Of those, the Dessie referral hospital and two private hospitals, namely Selam and Ethio general hospitals, were selected by using a simple random sampling technique. To determine the clients load in selected hospitals, the daily average flow of chronic disease patients at in-patient and out-patient clinics were estimated. Proportional allocation was made based on clients' load on the selected facilities (295: Dessie referral hospital; 67: Ethio general hospital; 60: Selam general hospital). Finally, a systematic random sampling method was employed to select study participants

\subsection{Data Collection Tool}

Structured interviewer-administered questionnaires were used for data collection, which consists of three sections.

(1) Socio-demographic characteristics: Age, educational level, sex, occupation, residency, family size, marital status, and number of house room.

(2) Clinical characteristics: Type of chronic diseases, duration of chronic disease, presence of co-morbidities, respiratory manifestations in the last two weeks, travel history to other areas, having social support, member of community health insurance, use of face mask and hand sanitizer.

(3) Depression, anxiety, and stress level: DASS-21 was 
used to measure the level of depression, anxiety, and stress. Each subscale has seven items. Each question has 0 to 3 responses $(0=$ did not apply to me at all, $1=$ applied to me to some degree or some of the time, $2=$ applied to me to a considerable degree or a good part of time, $3=$ applied to me very much or most of the time). The scores for depression, anxiety, and stress were calculated by summing each item. The DASS-21 score was multiplied by 2 to get the final score (DASS-42). Other researchers also use this multiplication to get DASS-42. Of DASS-21, question numbers 3, 5, 10, 13, 16, 17 , and 21 were used to assess depression, and it was divided into normal (0-9), mild depression (10-13), moderate depression (14 - 20), severe depression (21 - 27), and extremely severe depression (28-42). Question numbers 2, 4, $7,9,15,19$, and 20 were used to measure anxiety, and it was divided as normal (0-7), mild anxiety (8-9), moderate anxiety $(10-14)$, severe anxiety (15-19), and extremely severe anxiety (20 - 42). Moreover, question numbers 1, 6, 8, 11, 12, 14, and 18 formed stress subscale and divided into normal (0-14), mild stress (15-18), moderate stress (19-25), severe stress (26 - 33), and extremely severe stress (34-42). We used a reliable and valid tool to measure depression, anxiety, and stress levels. The internal consistency (Cronbach's alpha) of each subscale was high (Depression subscale 0.72; Anxiety subscale 0.77; and Stress subscale 0.70 ). The overall score of all items also had high consistency (Cronbach's alpha $=0.88)[33-35]$.

\subsection{Data Collection Procedure and Quality Control}

The data collection tool was translated from English to Amharic (the local language of the study area) and then back to
English to check its consistency. Pre-test was conducted by taking $10 \%$ of the sample size in the non-selected hospital (Baty hospital). Training was given to data collectors and supervisors. The data were collected under regular supervision after giving training for data collectors. Data collection was done by wearing a face mask and by maintaining the physical distance of two meters.

\subsection{Data Processing and Analysis}

Epidata 3.1 was used for data entry, and SPSS version 23.0 was utilized for analysis. Descriptive statistics of continuous variables were presented by using mean and discrete variables by using percentages and tables. Binary logistic regression analysis was tested along with $95 \%$ CI to assess the degree of association between outcome and independent variables. Variables that had a p-value of $<0.2$ in bivariate analysis were entered into a multivariate model to control confounding variables. A significant association was declared at the p-value of $<0.05$ in multivariate analysis.

\section{RESULTS}

\subsection{Depression, Anxiety and Stress Levels of Chronic Disease Patients During COVID-19 Pandemic}

Overall, 21.5\% (95\% CI: 17.5-25.6) of chronic diseases patients had depression during the COVID-19 pandemic. Furthermore, during the pandemic, $19.9 \%$ (95\% CI: 16.0-23.9) and $17.7 \%$ (95\% CI: $14.1-21.1)$ of participants showed anxiety and stress, respectively (Table 1).

Table 1. Depression, anxiety and stress level of chronic disease patients during COVID-19 pandemic in Dessie town government and private hospitals, Northeast Ethiopia, $2020(n=413)$.

\begin{tabular}{|c|c|c|c|}
\hline Depression Status & Frequency & Percentage & 95\% CI \\
\hline Normal (0-9) & 324 & 78.5 & $74.4-82.5$ \\
\hline Mild depression (10-13) & 42 & 10.2 & $7.4-13.3$ \\
\hline Moderate depression (14-20) & 41 & 9.9 & $6.9-12.6$ \\
\hline Severe depression (21-27) & 4 & 1.0 & $0.1-1.9$ \\
\hline Extremely Severe depression (28-42) & 2 & 0.5 & $0-1.2$ \\
\hline Overall depression(10-42) & 89 & 21.5 & $17.5-25.6$ \\
\hline Anxiety Status & & 76.1 & $76.1-84.0$ \\
\hline Normal (0-7) & 331 & 8.5 & $5.8-11.4$ \\
\hline Mild anxiety (8-9) & 35 & $9.1-11.9$ \\
\hline Moderate anxiety (10-14) & 38 & 1.2 & $0.2-2.4$ \\
\hline Severe anxiety (15-19) & 5 & 1.0 & $0.2-2.2$ \\
\hline Extremely severe anxiety (20-42) & 4 & 19.9 & $16.0-23.9$ \\
\hline Overall anxiety (8-42) & 82 & & \\
\hline Stress Status & & 82.3 & $78.9-85.9$ \\
\hline Normal (0-14) & 340 & 9.2 & $6.4-12.1$ \\
\hline Mild stress (15-18) & 38 & 5.8 & $3.6-8.0$ \\
\hline Moderate stress (19-25) & 24 & 1.9 & $0.7-3.5$ \\
\hline Severe stress (26-33) & 8 & 0.7 & $0-1.7$ \\
\hline Overall stress (15-42) & 72 & 17.7 & $14.1-21.1$ \\
\hline
\end{tabular}




\subsection{Factors Associated with Depression of Chronic Disease Patients During COVID-19 Pandemic}

In multivariate analysis, age $\geq 55$ years $(\mathrm{AOR}=2.350 ; 95 \%$ CI: 1.102-5.009; p-value: 0.027), female gender $(\mathrm{AOR}=2.102$; 95\% CI: 1.141-3.872; p-value: 0.017), urban residency (AOR $=2.352$; 95\% CI: 1.242-4.454; p-value: 0.009), living with chronic diseases for 5-10 years $(\mathrm{AOR}=2.451 ; 95 \% \mathrm{CI}$ : 1.224-4.909; $p$-value: 0.011 ) and $>10$ years $(\mathrm{AOR}=3.064 ; 95 \%$ CI: 1.356-6.923; p-value: 0.007$)$, and presence of additional comorbidities (AOR $=2.311 ; 95 \%$ CI: 1.108-4.819; p-value: $0.025)$ were significantly associated with depression of chronic disease patients during COVID-19 (Table 2).

Table 2. Factors associated with depression of chronic disease patients during COVID-19 pandemic in Dessie town government and private hospitals, Northeast Ethiopia, $2020(n=413)$.

\begin{tabular}{|c|c|c|c|c|c|}
\hline \multirow[t]{2}{*}{ Variables } & \multicolumn{2}{|c|}{ Depression } & \multicolumn{2}{|c|}{ OR(95\% CI) } & \multirow[b]{2}{*}{ P-value } \\
\hline & Yes N $(\%)$ & No N (\%) & COR & AOR & \\
\hline \multicolumn{6}{|l|}{ Age in year } \\
\hline $18-34$ & $15(10.8)$ & $124(89.2)$ & 1 & 1 & \\
\hline $35-54$ & $28(21.9)$ & $100(78.1)$ & $2.315(1.172-4.570)$ & $1.408(.632-3.137)$ & 0.403 \\
\hline$\geq 55$ & $46(31.5)$ & $100(68.5)$ & $3.803(2.006-7.208)$ & $2.350(1.102-5.009)$ & 0.027 \\
\hline \multicolumn{6}{|l|}{ Sex } \\
\hline Male & $30(15.2)$ & $168(84.8)$ & 1 & 1 & \\
\hline Female & $59(27.4)$ & $156(72.6)$ & $2.118(1.297-3.459)$ & $2.102(1.141-3.872)$ & 0.017 \\
\hline \multicolumn{6}{|l|}{ Occupation } \\
\hline Student & $8(13.1)$ & $53(86.9)$ & 1 & 1 & \\
\hline Employed & $17(20.0)$ & $68(80.0)$ & $1.656(.664-4.131)$ & $1.209(0.379-3.857)$ & 0.749 \\
\hline House wife & $41(25.8)$ & $118(74.2)$ & $2.302(1.010-5.247)$ & $1.183(0.358-3.907)$ & 0.782 \\
\hline Merchant & $1(4.8)$ & $20(94.2)$ & $0.331(0.039-2.820)$ & $0.369(0.037-3.638)$ & 0.393 \\
\hline Farmer & $20(33.3)$ & $40(66.7)$ & $3.312(1.324-8.287)$ & \begin{tabular}{|l|}
$1.977(0.498-7.857)$ \\
\end{tabular} & 0.333 \\
\hline Unemployed & $2(7.4)$ & $25(92.6)$ & $0.530(.105-2.680)$ & $0.267(0.039-1.814)$ & 0.177 \\
\hline \multicolumn{6}{|l|}{ Residency } \\
\hline Urban & $70(26.1)$ & $198(73.9)$ & $2.344(1.347-4.080)$ & $2.352(1.242-4.454)$ & 0.009 \\
\hline Rural & $19(13.1)$ & 126(86.9) & \begin{tabular}{|c|}
1 \\
\end{tabular} & \begin{tabular}{|c|}
1 \\
\end{tabular} & \\
\hline \multicolumn{6}{|l|}{ Marital status } \\
\hline Not married & $14(16.3)$ & $72(83.7)$ & 1 & 1 & \\
\hline Married & $60(20.9)$ & $227(79.1)$ & $1.359(0.717-2.576)$ & $1.085(0.422-2.792)$ & 0.866 \\
\hline Divorced & $7(46.7)$ & $8(53.3)$ & $4.500(1.404-14.423)$ & $3.085(0.731-13.011)$ & 0.125 \\
\hline Widowed & $8(32.0)$ & $17(68.0)$ & $2.420(0.875-6.690)$ & $1.120(0.285-4.405)$ & 0.871 \\
\hline \multicolumn{6}{|c|}{ Number of house room } \\
\hline 1 & $17(20.5)$ & $66(79.5)$ & $1.101(0.588-2.058)$ & $0.860(0.414-1.785)$ & 0.685 \\
\hline 2 & $28(28.6)$ & $70(71.4)$ & \begin{tabular}{|l|}
$1.709(0.988-2.955)$ \\
\end{tabular} & $1.425(0.681-2.983)$ & 0.347 \\
\hline$>=3$ & $44(19.0)$ & $188(81.0)$ & \begin{tabular}{|c|}
1 \\
\end{tabular} & \begin{tabular}{|c|}
1 \\
\end{tabular} & \\
\hline \multicolumn{6}{|c|}{ Duration of chronic diseases in years } \\
\hline$<5$ & $50(16.3)$ & $257(83.7)$ & $\begin{array}{l}1 \\
\end{array}$ & \begin{tabular}{|c|}
1 \\
\end{tabular} & \\
\hline $5-10$ & $21(32.8)$ & $43(67.2)$ & $2.510(1.373-4.589)$ & $2.451(1.224-4.909)$ & 0.011 \\
\hline$>10$ & $18(42.9)$ & $24(57.1)$ & $3.855(1.949-7.625)$ & $3.064(1.356-6.923)$ & 0.007 \\
\hline \multicolumn{6}{|c|}{ Presence comorbidities } \\
\hline Yes & $24(38.1)$ & $39(61.9)$ & $2.698(1.518-4.797)$ & $2.311(1.108-4.819)$ & 0.025 \\
\hline No & $65(18.6)$ & $285(81.4)$ & \begin{tabular}{|c|}
1 \\
\end{tabular} & 1 & \\
\hline \multicolumn{6}{|c|}{ Presence of respiratory symptoms in the last 2 weeks } \\
\hline Yes & $17(41.5)$ & $24(58.5)$ & $2.951(1.507-5.782)$ & $2.199(.789-6.130)$ & 0.132 \\
\hline No & $72(19.4)$ & $300(80.6)$ & \begin{tabular}{|c|}
1 \\
\end{tabular} & 1 & \\
\hline \multicolumn{6}{|c|}{ Travel history to other areas in the last 2 weeks } \\
\hline Yes & $7(43.8)$ & $9(56.3)$ & $2.988(1.080-8.262)$ & $0.553(0.135-2.269)$ & 0.411 \\
\hline No & $82(20.7)$ & $315(79.3)$ & 1 & 1 & \\
\hline \multicolumn{6}{|c|}{ Having social support } \\
\hline Yes & $62(18.7)$ & $270(81.3)$ & 1 & 1 & \\
\hline No & $27(33.3)$ & $54(66.7)$ & $2.177(1.271-3.730)$ & $1.689(.875-3.260)$ & 0.118 \\
\hline
\end{tabular}




\subsection{Factors Associated with Anxiety of Chronic Disease Patients During COVID-19 Pandemic}

In multivariate analysis, age group of 35-54 years (AOR=2.169; 95\%CI: 1.033-4.554; p-value: 0.041$)$ and $\geq 55$ years (AOR=2.335; 95\% CI: 1.151-4.736; $p$-value: 0.019$)$ were more likely to have anxiety compared to those who had age 18-34 years. Females had two times higher anxiety (AOR=2.062; 95\% CI: 1.177-3.613; p-value: 0.011) than males, and patients with the presence of additional comorbidities were three times more likely to have anxiety (AOR=2.809; 956\% CI: 1.456-5.418; p-value: 0.002) as compared to those who had no other comorbidities. Moreover, patients who had no social support were two times more likely to have anxiety $(\mathrm{AOR}=2.041 ; 956 \% \mathrm{CI}: 1.106-3.764$; p-value: 0.022) compared to those who had social support (Table 3 ).

\subsection{Factors Associated with the Stress of Chronic Disease Patients During COVID-19 Pandemic}

In multivariate analysis, urban residency $(\mathrm{AOR}=2.041$; 95\% CI: 1.036-4.021; p-value: 0.039 ), presence of respiratory manifestations in the last 2 weeks $(\mathrm{AOR}=4.522 ; 95 \% \mathrm{CI}$ : 1.638-12.482; p-value: 0.004 ), travel history to other areas in the last 2 weeks ( $\mathrm{AOR}=4.070 ; 95 \% \mathrm{CI}: 1.059-15.639$; $\mathrm{p}$-value: $0.041)$, and hand sanitizer use (AOR $=2.218 ; 95 \% \mathrm{CI}$ : 1.227-4.008; p-value: 0.008 ) were significantly associated with stress of chronic disease patients during the current pandemic (Table 4).

Table 3. Factors associated with anxiety of chronic disease patients during COVID-19 pandemic in Dessie town government and private hospitals, Northeast Ethiopia, $2020(n=413)$.

\begin{tabular}{|c|c|c|c|c|c|}
\hline \multirow[t]{2}{*}{ Variables } & \multicolumn{2}{|c|}{ Anxiety } & \multicolumn{2}{|c|}{ OR(95\% CI) } & \multirow[t]{2}{*}{ P-value } \\
\hline & Yes N (\%) & No N (\%) & COR & AOR & \\
\hline \multicolumn{6}{|l|}{ Age in year } \\
\hline $18-34$ & $16(11.5)$ & $123(88.5)$ & 1 & 1 & \\
\hline $35-54$ & $29(22.7)$ & 99(77.3) & $2.252(1.158-4.380)$ & $2.169(1.033-4.554)$ & 0.041 \\
\hline$\geq 55$ & $37(25.3)$ & $109(74.7)$ & $2.610(1.37-4.952)$ & $2.335(1.151-4.736)$ & 0.019 \\
\hline \multicolumn{6}{|l|}{ Sex } \\
\hline Male & $28(14.1)$ & $170(85.9)$ & 1 & 1 & \\
\hline Female & $54(25.1)$ & 161(74.9) & $2.036(1.229-3.373)$ & $2.062(1.177-3.613)$ & .011 \\
\hline \multicolumn{6}{|l|}{ Marital status } \\
\hline Not married & $13(15.1)$ & $73(84.9)$ & 1 & 1 & \\
\hline Married & $54(18.8)$ & $233(81.2)$ & $1.301(.673-2.518)$ & \begin{tabular}{|l|}
$1.003(0.475-2.118)$ \\
\end{tabular} & 0.993 \\
\hline Divorced & $6(40.0)$ & $9(60.0)$ & $3.744(1.139-12.301)$ & 2.673(0.739-9.671) & 0.134 \\
\hline Widowed & $9(36.0)$ & $16(64.0)$ & $3.159(1.153-8.651)$ & $1.880(0.607-5.829)$ & 0.274 \\
\hline \multicolumn{6}{|c|}{ Duration of chronic diseases in years } \\
\hline$<5$ & $56(18.2)$ & $251(81.8)$ & 1 & 1 & \\
\hline $5-10$ & $12(18.8)$ & $52(81.3)$ & $1.034(0.518-2.065)$ & $0.796(0.369-1.718)$ & 0.561 \\
\hline$>10$ & $14(33.3)$ & $28(66.7)$ & 2.241(1.109-4.531) & $1.405(0.629-3.141)$ & 0.407 \\
\hline \multicolumn{6}{|c|}{ Presence comorbidities } \\
\hline Yes & $25(39.7)$ & $38(60.3)$ & $3.382(1.895-6.034)$ & $2.809(1.456-5.418)$ & 0.002 \\
\hline No & $57(16.3)$ & $293(83.7)$ & 1 & 1 & \\
\hline \multicolumn{6}{|c|}{ Presence of respiratory symptoms in the last 2 weeks } \\
\hline Yes & $15(36.6)$ & $26(63.4)$ & $2.626(1.320-5.227)$ & $1.536(0.583-4.044)$ & 0.385 \\
\hline No & $67(18.0)$ & $305(82.0)$ & \begin{tabular}{|c|}
1 \\
\end{tabular} & 1 & \\
\hline \multicolumn{6}{|c|}{ Travel history to other areas in the last 2 weeks } \\
\hline Yes & $7(43.8)$ & $9(56.3)$ & $3.339(1.205-9.253)$ & $2.576(0.611-10.858)$ & 0.197 \\
\hline No & $75(18.9)$ & $322(81.1)$ & 1 & 1 & \\
\hline \multicolumn{6}{|c|}{ Having social support } \\
\hline Yes & $56(16.9)$ & $276(83.1)$ & \begin{tabular}{|c|}
1 \\
\end{tabular} & 1 & \\
\hline No & $26(32.1)$ & \begin{tabular}{|l|}
$55(67.9)$ \\
\end{tabular} & $2.330(1.347-4.029)$ & \begin{tabular}{|l|}
$2.041(1.106-3.764)$ \\
\end{tabular} & 0.022 \\
\hline \multicolumn{6}{|c|}{ Hand sanitizer use } \\
\hline Yes & $28(25.5)$ & $82(74.5)$ & \begin{tabular}{|l|}
$1.575(0.936-2.649)$ \\
\end{tabular} & $1.536(.864-2.730)$ & 0.143 \\
\hline No & $54(17.8)$ & $249(82.2)$ & 1 & 1 & \\
\hline
\end{tabular}


Table 4. Factors associated with the stress of chronic disease patients during COVID-19 pandemic in Dessie town government and private hospitals, Northeast Ethiopia, $2020(n=413)$

\begin{tabular}{|c|c|c|c|c|c|}
\hline \multirow[t]{2}{*}{ Variables } & \multicolumn{2}{|c|}{ Stress } & \multicolumn{2}{|c|}{ OR(95\% CI) } & \multirow[t]{2}{*}{ P-value } \\
\hline & Yes N (\%) & No N (\%) & COR & AOR & \\
\hline \multicolumn{6}{|l|}{ Age in year } \\
\hline $18-34$ & $19(13.7)$ & $120(86.3)$ & 1 & & \\
\hline $35-54$ & $30(23.4)$ & \begin{tabular}{|l|}
$98(76.6)$ \\
\end{tabular} & $1.933(1.026-3.643)$ & $1.477(0.672-3.249)$ & 0.332 \\
\hline$\geq 55$ & $24(16.4)$ & 122(83.6) & $1.242(0.647-2.386)$ & $1.314(0.599-2.884)$ & 0.496 \\
\hline \multicolumn{6}{|l|}{ Sex } \\
\hline Male & $27(13.6)$ & 171(86.4) & 1 & & \\
\hline Female & $46(21.4)$ & $169(78.6)$ & $1.724(1.024-2.901)$ & $1.397(.738-2.645)$ & 0.304 \\
\hline \multicolumn{6}{|l|}{ Marital status } \\
\hline Not married & $13(15.1)$ & $73(84.9)$ & 1 & & \\
\hline Married & $52(18.1)$ & $235(81.9)$ & $1.243(0.641-2.409)$ & $0.722(0.290-1.792)$ & 0.482 \\
\hline Divorced & $6(40.0)$ & $9(60.0)$ & $3.744(1.139-12.301)$ & $1.839(0.442-7.650)$ & 0.402 \\
\hline Widowed & $2(8.0)$ & $23(92.0)$ & $0.488(0.103-2.325)$ & $0.292(0.050-1.688)$ & 0.169 \\
\hline \multicolumn{6}{|l|}{ Occupation } \\
\hline Student & $8(13.1)$ & $53(86.9)$ & 1 & & \\
\hline Employed & $17(20.0)$ & $68(80.0)$ & \begin{tabular}{|l}
$1.656(0.664-4.131)$ \\
\end{tabular} & $1.267(0.388-4.144)$ & 0.695 \\
\hline House wife & $38(23.9)$ & 121(76.1) & $2.081(0.909-4.762)$ & $1.449(0.447-4.692)$ & 0.536 \\
\hline Merchant & $4(19.0)$ & \begin{tabular}{|l|}
$17(81.0)$ \\
\end{tabular} & $1.559(0.417-5.828)$ & $1.470(0.3196 .765-)$ & 0.621 \\
\hline Farmer & $4(6.7)$ & $56(93.3)$ & $0.473(0.135-1.664)$ & $0.231(0.042-1.275)$ & 0.093 \\
\hline Unemployed & $2(7.4)$ & $25(92.6)$ & $0.530(0.105-2.680)$ & $0.422(0.072-2.461)$ & 0.337 \\
\hline \multicolumn{6}{|l|}{ Residency } \\
\hline Urban & $58(21.6)$ & $210(78.4)$ & $2.394(1.303-4.398)$ & $2.041(1.036-4.021)$ & 0.039 \\
\hline Rural & $15(10.3)$ & $130(89.7)$ & 1 & & \\
\hline \multicolumn{6}{|l|}{ Family size } \\
\hline $1-3$ & $22(13.2)$ & $145(86.8)$ & 1 & & \\
\hline$\geq 4$ & $51(20.7)$ & $195(79.3)$ & $1.724(1.000-2.970)$ & $1.775(.943-3.342)$ & 0.076 \\
\hline \multicolumn{6}{|c|}{ Presence comorbidities } \\
\hline Yes & $17(27.0)$ & $46(73.0)$ & $1.940(1.038-3.626)$ & $1.621(0.750-3.507)$ & 0.220 \\
\hline No & $56(16.0)$ & $294(84.0)$ & \begin{tabular}{|c|}
1 \\
\end{tabular} & & \\
\hline \multicolumn{6}{|c|}{ Presence of respiratory symptoms in the last 2 weeks } \\
\hline Yes & $15(36.6)$ & $26(63.4)$ & $3.123(1.560-6.255)$ & $4.522(1.638-12.482)$ & 0.004 \\
\hline No & $58(15.6)$ & $314(84.4)$ & 1 & & \\
\hline \multicolumn{6}{|c|}{ Travel history to other areas in the last 2 weeks } \\
\hline Yes & $7(43.8)$ & $9(56.3)$ & 3.901(1.403-10.844) & $4.070(1.059-15.639)$ & 0.041 \\
\hline No & $66(16.6)$ & $331(83.4)$ & 1 & & \\
\hline \multicolumn{6}{|l|}{ Face mask use } \\
\hline Yes & $56(21.5)$ & $205(78.5)$ & $2.169(1.209-3.892)$ & $1.842(0.956-3.549)$ & 0.068 \\
\hline No & $17(11.2)$ & $135(88.8)$ & $\begin{array}{c}1 \\
\end{array}$ & 1 & \\
\hline \multicolumn{6}{|c|}{ Hand sanitizer use } \\
\hline Yes & $33(30.0)$ & \begin{tabular}{|l|}
$77(70.0)$ \\
\end{tabular} & $2.818(1.665-4.769)$ & $2.218(1.227-4.008)$ & 0.008 \\
\hline No & $40(13.2)$ & $263(86.8)$ & 1 & & \\
\hline
\end{tabular}

AOR: Adjusted odds ratio; COR: Crude odds ratio; N: Frequency; OR: odds ratio.

\section{DISCUSSION}

Currently, COVID-19 is a major global health problem, including in Ethiopia. The current study investigated the depression, anxiety, and stress level of chronic disease patients. This finding could help inform policymakers, health professionals, and non-governmental organizations to alleviate the mental problems of chronic disease patients during the period of COVID-19.
In our study, $21.5 \%$ (95\% CI: 17.5-25.6) of chronic disease patients had depression during the COVID-19 pandemic from mild to extremely severe cases. This finding was supported by studies conducted in China (20.1\%) [25], UK (22.12\%) [30], and Nigeria (23.5\%) [36]. However, it was lower than that found in studies in China (37.1\%) [27], (53.5\%) [37], Japan (43.1\%) [38], Nepal (34\%) [39], India (38.9\%) [31], Iraq (44.9\%) [29] and Italy (32.8\%) [32]. The finding is higher than that found in another study in China (17.17\%) [40]. These 
discrepancies might be due to the difference in COVID-19 burden in different settings, a time gap of studies in various settings and countries, and the presence of differences in perceived susceptibility towards the pandemic in various study areas.

With regard to anxiety, $19.9 \%$ (95\% CI: $16.0-23.9)$ of patients with chronic disease had anxiety. This is in line with studies done in Italy (18.7\%) [32] and UK (21.63\%) [30]. However, this result is lower than the studies conducted in Nigeria (49.6\%) [36], Spain (32.4\%) [41], Iraq (47.1\%\%) [29], India (43\%) [31], Nepal (31\%) [39], Japan (33.2\%) [38] and China (29\%) [27]. However, it is higher than a study done in some regions of China (6.33\%) [40]. These discrepancies between this and other studies might be due to the difference in perceived severity and perceived susceptibility towards COVID-19 and time gaps of studies in various countries.

In our study, the overall stress from mild to extremely severe stress was 72 (17.7\%) (95\% CI: 14.1-21.1). This finding was similar with a study carried out in Iraq (17.5\%) [29], but it is lower than studies conducted in Spain (37\%) [41], India (35.7\%) [31], China (32.1\%) [24] and Italy (27.2\%) [32]. This discrepancy could be related to the difference in the burden of the pandemic in different study areas, the time gap between studies, and the difference in socio-demographic profile.

Overall, our study revealed that depression, anxiety, and stress were common in chronic disease patients during the COVID-19 pandemic, which needs interventions by the government, local administrations, health care workers, and researchers as well as non-governmental organizations.

In our study, associated factors of depression, anxiety, and stress were also identified. Age $\geq 55$ years were associated with depression symptoms as compared to age from 18-34 years. Age $\geq 55$ years and 35-54 years were also significantly associated with the anxiety level of chronic disease patients as compared to age 18-34 years. This finding contradicts a study done in Japan where depressive symptoms and anxiety symptoms were higher for young and middle-aged respondents compared to older respondents [38]. A study done in China also revealed that young aged individuals (21-40 years) were more vulnerable to mental illnesses [27]. This discrepancy could be explained by the fact that older aged people in this study may have more economic problems as compared to Japan and China, that end up with higher depression and anxiety during COVID-19.

Female gender was significantly associated with anxiety and depression of chronic diseases patients during COVID-19, which was similar to studies conducted in China, Iraq, Italy, and Nepal [24, 29, 32, 39]. This might be related to genderbased violence and the economical influence on females which made them develop depression and anxiety over the COVID-19 burden. The finding was also supported by other studies in which females were more vulnerable to experiencing and developing post-traumatic symptoms than males [42].

Urban residency and the presence of comorbidities were significantly associated with depression of chronic disease patients. A study carried out in Turkey also revealed that the pandemic had a greater effect on urban dwellers and on those who had comorbidities [43]. Duration of living with chronic diseases 5-10 years and $>10$ years were also significantly associated with depression of chronic disease patients during the current pandemic as compared to less than 5 years. This implies that as the duration of the disease becomes longer, the burden on mental health becomes high.

People having no social support were more likely to have anxiety compared to those with social support. This is similar to a study carried out in China where social support and anxiety were negatively correlated. This suggested that the anxiety level of patients having chronic diseases should be monitored during the pandemic [44].

The presence of respiratory manifestations in the past two weeks was significantly associated with the stress level of chronic disease patients during the current pandemic. This is in line with a study conducted on populations of Spain where significant positive associations were found between stress level and COVID-19 symptoms [41]. Travel history in the last 2 weeks and hand sanitizer use also had an association with stress levels. The possible reason might be that as people travel to other areas during the pandemic, they may over think about the transmission of the diseases during their journey, which might lead to stress. More stressed individuals might use hand sanitizer more frequently as they might think about the COVID-19 pandemic over and over again.

This study had limitations. Due to the cross-sectional nature of the study, it is difficult to conclude the prolonged effect of COVID-19. In addition, we tried to compare our findings with general population studies due to the availability of limited researches on patients with chronic diseases, depression, anxiety, and stress levels during the COVD-19 pandemic.

\section{CONCLUSION}

A noteworthy number of chronic disease patients had depression, anxiety, and stress during the COVID-19 pandemic. Age $\geq 55$ years, being female, urban residency, living with chronic diseases for a longer duration, and presence of additional comorbidities were significantly associated with depression of patients during COVID-19. During the pandemic, older age, female gender, presence of comorbidities, and no social support were independently associated with anxiety of chronic disease patients. Furthermore, urban residency, hand sanitizer use, presence of respiratory manifestations, and travel history to other areas in the last two weeks were factors associated with stress of chronic disease patients during the pandemic. Therefore, governmental and non-governmental organizations, health professionals, media, and hospital administrators should be involved in decreasing the depression, anxiety, and stress of chronic disease patients during the pandemic. Since COVID-19 is still an ongoing public health problem, the need for mental health interventions throughout the remainder of the pandemic is crucial. Moreover, we encourage researchers to conduct comparative longitudinal studies to assess depression, anxiety, and stress level of chronic disease patients before and after the onset of the COVID-19 pandemic. 


\section{LIST OF ABBREVIATIONS}

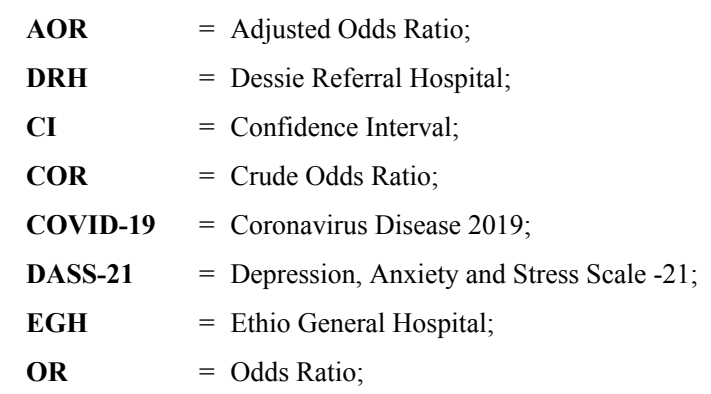
SARS-CoV-2 $=$ Severe Acute Respiratory Syndrome Coronavirus-2;
SGH = Selam General Hospital;
SD $\quad=$ Standard Deviation;
SPSS $\quad=$ Statistical Program for Social Sciences;
UK = United Kingdom

\section{ETHICS APPROVAL AND CONSENT TO} PARTICIPATE

The Ethical clearance was obtained from Wollo University College of Medicine and Health Science Research Ethical Review Committee. The reference number was WU/324/T-01/2020).

\section{HUMAN AND ANIMAL RIGHTS}

No animals were used in this research. All human research procedures were followed in accordance with the ethical standards of the research review committee and with the Helsinki Declaration of 1975, as revised in 2013.

\section{CONSENT FOR PUBLICATION}

Informed consent has been obtained from all participants.

\section{STANDARDS OF REPORTING}

The authors followed the STROBE guidelines to report this research finding.

\section{AVAILABILITY OF DATA AND MATERIALS}

The authors confirm that the data supporting the findings of this research are available within the article. If the readers need more data, please contact the corresponding author [S.G.A]

\section{FUNDING}

This research work financially supported by Wollo University. The funding source had no role in the study design, data collection, analysis and interpretations of data.

\section{CONFLICT OF INTEREST}

The authors declare no conflict of interest, financial or otherwise.

\section{ACKNOWLEDGEMENTS}

The authors would like to appreciate Wollo University for providing financial support to conduct this research. We would like to acknowledge the data collectors and supervisors for their time and commitment. Our appreciation also goes to hospital administrators for their cooperation.

\section{REFERENCES}

[1] WHO. Coronavirus disease 2019 (COVID-19)Situation Report -51 https://www.who.int/docs/default-source/coronaviruse/situation-report s/20200311-sitrep-51-covid-19.pdf?sfvrsn=1ba62e57_102020.

[2] Guan WJ, Ni ZY, Hu Y, et al. Clinical characteristics of coronavirus disease 2019 in China. N Engl J Med 2020; 382(18): 1708-20. [http://dx.doi.org/10.1056/NEJMoa2002032] [PMID: 32109013]

[3] Wang D, Hu B, Hu C, et al. Clinical characteristics of 138 hospitalized patients with 2019 novel coronavirus-infected pneumonia in Wuhan, China. JAMA 2020; 323(11): 1061-9. [http://dx.doi.org/10.1001/jama.2020.1585] [PMID: 32031570]

[4] Zhou F, Yu T, Du R, et al. Clinical course and risk factors for mortality of adult inpatients with COVID-19 in Wuhan, China: A retrospective cohort study. Lancet 2020; 395(10229): 1054-62. [http://dx.doi.org/10.1016/S0140-6736(20)30566-3] [PMID: 32171076]

[5] Chen N, Zhou M, Dong X, et al. Epidemiological and clinical characteristics of 99 cases of 2019 novel coronavirus pneumonia in Wuhan, China: A descriptive study. Lancet 2020; 395(10223): 507-13. [http://dx.doi.org/10.1016/S0140-6736(20)30211-7] [PMID: 32007143]

[6] Centers for Disease Control Prevention. Groups at higher risk for severe illness. Accessed 2020.

[7] Yang J, Zheng Y, Gou X, Pu K, Chen Z, Guo Q, et al. Prevalence of comorbidities and its effects in coronavirus disease 2019 patient: A systematic review and meta-analysis. Int J Infect Dis 2020; 94: 91-5. [http://dx.doi.org/10.1016/j.ijid.2020.03.017] [PMID: 32173574]

[8] Shereen MA, Khan S, Kazmi A, Bashir N, Siddique R. COVID-19 infection: Origin, transmission, and characteristics of human coronaviruses. J Adv Res 2020; 24: 91-8.

[http://dx.doi.org/10.1016/j.jare.2020.03.005] [PMID: 32257431]

[9] Phan LT, Nguyen TV, Luong QC, et al. Importation and human-tohuman transmission of a novel coronavirus in Vietnam. N Engl J Med 2020; 382(9): 872-4.

[http://dx.doi.org/10.1056/NEJMc2001272] [PMID: 31991079]

[10] Parry J. China coronavirus: cases surge as official admits human to human transmission. British Medical Journal Publishing Group 2020.

[11] Li Q, Guan X, Wu P, et al. Early transmission dynamics in Wuhan, China, of novel coronavirus-infected pneumonia. N Engl J Med 2020; 382(13): 1199-207.

[http://dx.doi.org/10.1056/NEJMoa2001316] [PMID: 31995857]

[12] WHO. WHO Coronavirus Disease (COVID-19) Dashboard: Situation by Country, Territory \& Area https://covid19.who.int/table2020.

[13] Takes I. Mitigating the COVID Economic Crisis: Act Fast and Do Whatever.

[14] World Health Organization. Coronavirus disease 2019 (COVID-19): situation report. 2020

[15] Baloch S, Baloch MA, Zheng T, Pei X. The Coronavirus Disease 2019 (COVID-19) Pandemic. Tohoku J Exp Med 2020; 250(4): 271-8. [http://dx.doi.org/10.1620/tjem.250.271] [PMID: 32321874]

[16] Kanu IA. COVID-19 and the economy: An African perspective. Journal of African Studies and Sustainable Development 2020;3(2)

[17] Ataguba JE. COVID-19 pandemic, a war to be won: understanding its economic implications for Africa. Springer 2020.

[18] Rosenthal PJ, Breman JG, Djimde AA, et al. COVID-19: Shining the light on Africa. Am J Trop Med Hyg 2020; 102(6): 1145-8. [http://dx.doi.org/10.4269/ajtmh.20-0380] [PMID: 32372749]

[19] Ali I, Alharbi OML. COVID-19: Disease, management, treatment, and social impact. Sci Total Environ 2020; 728: 138861.

[http://dx.doi.org/10.1016/j.scitotenv.2020.138861] [PMID: 32344226]

[20] Yusuf S. COVID-19 and political stability in Ethiopia, 2020. Available from:

https://www.africaportal.org/publications/covid-19-and-political-stabil ity-ethiopia/

[21] Davies. NG, Sweeney S, Torres Rueda S, et al. The impact of Coronavirus disease 2019 (COVID-19) on health systems and household resources in Africa and South Asia. MedRxiv 2020. [http://dx.doi.org/10.1101/2020.05.06.20092734]

[22] Paintsil E. COVID-19 threatens health systems in sub-Saharan Africa: The eye of the crocodile. J Clin Invest 2020; 130(6): 2741-4. 
[http://dx.doi.org/10.1172/JCI138493] [PMID: 32224550]

[23] Blanton RE, Mock NB, Hiruy HN, et al. African Resources and the Promise of Resilience against COVID-19. Am J Trop Med Hyg 2020; 103(2): 539-41.

[http://dx.doi.org/10.4269/ajtmh.20-0470] [PMID: 32500851]

[24] Wang C, Pan R, Wan X, et al. Immediate psychological responses and associated factors during the initial stage of the 2019 coronavirus disease (COVID-19) epidemic among the general population in China. Int J Environ Res Public Health 2020; 17(5): 1729.

[http://dx.doi.org/10.3390/ijerph17051729] [PMID: 32155789]

[25] Huang Y, Zhao N. Generalized anxiety disorder, depressive symptoms and sleep quality during COVID-19 outbreak in China: A web-based cross-sectional survey. Psychiatry Res 2020; 288: 112954.

[http://dx.doi.org/10.1016/j.psychres.2020.112954] [PMID: 32325383]

[26] Moghanibashi-Mansourieh A. Assessing the anxiety level of Iranian general population during COVID-19 outbreak. Asian J Psychiatr 2020; 51: 102076 .

[http://dx.doi.org/10.1016/j.ajp.2020.102076] [PMID: 32334409]

[27] Ahmed MZ, Ahmed O, Aibao Z, Hanbin S, Siyu L, Ahmad A. Epidemic of COVID-19 in China and associated Psychological Problems. Asian J Psychiatr 2020; 51: 102092.

[http://dx.doi.org/10.1016/j.ajp.2020.102092] [PMID: 32315963]

[28] Zhou S-J, Zhang L-G, Wang L-L, et al. Prevalence and sociodemographic correlates of psychological health problems in Chinese adolescents during the outbreak of COVID-19. Eur Child Adolesc Psychiatry 2020; 29(6): 749-58.

[http://dx.doi.org/10.1007/s00787-020-01541-4] [PMID: 32363492]

[29] Othman N. Depression, anxiety, and stress in the time of COVID-19 pandemic in Kurdistan region, Iraq. Kurdistan. J Applied Res 2020; $37-44$.

[http://dx.doi.org/10.24017/kjar]

[30] Shevlin M, Nolan E, Owczarek M, et al. COVID-19-related anxiety predicts somatic symptoms in the UK population. Br J Health Psychol 2020; 25(4): 875-82.

[http://dx.doi.org/10.1111/bjhp.12430] [PMID: 32458550]

[31] Kazmi SSH, Hasan K, Talib S, et al. COVID-19 and lockdwon: A study on the impact on mental health. Available at SSRN 3577515 2020 .

[http://dx.doi.org/10.2139/ssrn.3577515]

[32] Mazza C, Ricci E, Biondi S, et al. A nationwide survey of psychological distress among italian people during the COVID-19 pandemic: Immediate psychological responses and associated factors. Int J Environ Res Public Health 2020; 17(9): 3165.

[http://dx.doi.org/10.3390/ijerph17093165] [PMID: 32370116]

[33] Lovibond SH, Lovibond PF. Manual for the Depression Anxiety Stress Scales. 2nd ed. Sydney: Psychology Foundation 1995.

[34] Antony MM, Bieling PJ, Cox BJ, Enns MW, Swinson RP.
Psychometric properties of the 42-item and 21-item versions of the Depression Anxiety Stress Scales in clinical groups and a community sample. Psychol Assess 1998; 10(2): 176.

[http://dx.doi.org/10.1037/1040-3590.10.2.176]

[35] Ho CSH, Tan ELY, Ho RCM, Chiu MYL. Relationship of anxiety and depression with respiratory symptoms: Comparison between depressed and non-depressed smokers in Singapore. Int J Environ Res Public Health 2019; 16(1): 163.

[http://dx.doi.org/10.3390/ijerph16010163] [PMID: 30626156]

[36] Agberotimi SF, Akinsola OS, Oguntayo R, Olaseni AO. Interactions between socioeconomic status and mental health outcomes in the nigerian context amid covid-19 pandemic: A comparative study. Frontiers in Psychology 2020; 11: 2655.

[http://dx.doi.org/10.3389/fpsyg.2020.559819]

[37] Liu D, Ren Y, Yan F, Li Y, Xu X, Yu X, et al. Psychological Impact and Predisposing Factors of the Coronavirus Disease 2019 (COVID-19). Pandemic on General Public in China 2020.

[38] Ueda M, Stickley A, Sueki H, Matsubayashi T. Mental Health Status of the General Population during the COVID-19 Pandemic: A Crosssectional National Survey in Japan medRxiv 2020

[http://dx.doi.org/10.1101/2020.04.28.20082453]

[39] Sigdel A, Bista A, Bhattarai N, Poon BC, Giri G, Marqusee H. Depression, Anxiety and Depression-anxiety comorbidity amid COVID-19 Pandemic: An online survey conducted during lockdown in Nepal medRxiv 2020.

[http://dx.doi.org/10.1101/2020.04.30.20086926]

[40] Wang Y, Di Y, Ye J, Wei W. Study on the public psychological states and its related factors during the outbreak of coronavirus disease 2019 (COVID-19) in some regions of China. Psychol Health Med 2021; 26(1): 13-22.

[http://dx.doi.org/10.1080/13548506.2020.1746817]

[PMID: 32223317]

[41] Odriozola-González P, Planchuelo-Gómez Á, Irurtia-Muñiz MJ, et al. Psychological symptoms of the outbreak of the COVID-19 confinement in Spain. J Health Psychol 2020; 1359105320967086. [http://dx.doi.org/10.31234/osf.io/mq4fg]

[42] Sareen J, Erickson J, Medved MI, et al. Risk factors for post-injury mental health problems. Depress Anxiety 2013; 30(4): 321-7. [http://dx.doi.org/10.1002/da.22077] [PMID: 23408506]

[43] Özdin S, Bayrak Özdin S.. Levels and predictors of anxiety, depression and health anxiety during COVID-19 pandemic in Turkish society: The importance of gender. Int J Soc Psychiatry 2020; 66(5): 504-11. [http://dx.doi.org/10.1177/0020764020927051] [PMID: 32380879]

[44] Cao W, Fang Z, Hou G, et al. The psychological impact of the COVID-19 epidemic on college students in China. Psychiatry Res 2020; $287: 112934$.

[http://dx.doi.org/10.1016/j.psychres.2020.112934] [PMID: 32229390]

\section{(c) 2021 Addis et al.}

This is an open access article distributed under the terms of the Creative Commons Attribution 4.0 International Public License (CC-BY 4.0), a copy of which is available at: https://creativecommons.org/licenses/by/4.0/legalcode. This license permits unrestricted use, distribution, and reproduction in any medium, provided the original author and source are credited. 